O eixo e a roda, Belo Horizonte, v. 24, n. 2, p. 71-84, 2015

\title{
A rotina de sinha Vitória: sonhos num mundo recalcitrante
}

\section{Sinha Vitória's routine: dreams in a recalcitrant world}

Hermenegildo José de Menezes Bastos

Universidade de Brasília (UnB), Brasília, Distrito Federal, Brasil.

hjbastos@unb.br

Resumo: Neste trabalho procuramos salientar o caráter não determinista de Vidas secas a partir da leitura do capítulo "Sinha Vitória". Aí representa-se e apresenta-se o dia a dia massacrante da personagem no espaço físico e social da fazenda, num mundo cerrado e opressivo de onde ela e os seus aparentemente não podem sair. Tomamos o capítulo como um microcosmo da vida brasileira dos anos 30 do século passado. Evidenciam-se aí os limites estruturais do capitalismo brasileiro, mas, ao mesmo tempo, discute-se a possibilidade de sua superação. Sinha Vitória vive essa situação extrema sem se deixar reduzir na sua humanidade, reflete sobre as possibilidades extremas de superá-la. A leitura que o intelectual Graciliano Ramos faz do Brasil confunde-se com a leitura da personagem, mas ao mesmo tempo distancia-se.

Palavras-chave: Vidas secas; realismo; figuração da humanidade da personagem; os limites estruturais do capitalismo; as possibilidades objetivas de sua superação. 
Abstract: In the present article we intend to emphasize the nondeterministic nature of Vidas secas (Barren Lives) departing from a reading of the chapter "Sinha Vitória". It portrays the character's tiring routine in the physical and social space of the farm, in a closed and oppressive world from which she and her kin apparently can not escape. The chapter is taken as a microcosm of Brazilian life in the 1930s. The structural limits of Brazilian capitalism are made clear, but at the same time the possibilities of overcoming it are discussed. Sinha Vitória lives this extreme situation without letting her humanity be reduced and reflects on the extreme possibilities of overcoming her predicament. The analysis of Brazil offered by the intellectual Graciliano Ramos blends in with that of the character, but at the same time it distances itself from it.

Keywords: Vidas secas (Barren Lives); realism; character's humanity portrayal; structural limits of capitalism; objective possibilities of overcoming.

Recebido em 25 de maio de 2015.

Aprovado em 28 de julho de 2015.

“O mundo é grande.” (Fabiano em Vidas secas).

A unidade do capítulo "Sinha Vitória" resulta da conjugação de duas projeções das experiências da personagem: por um lado, o desejo de ter uma cama de couro como a de seu Tomás da bolandeira, por outro, o medo de que a seca retorne. Não são meros exemplos de alegorias transcendentes. São duas projeções extremas e contrapostas (mas conjugadas), imanentes à vivência da personagem: a primeira é um desejo de conquistar a dignidade humana, propiciado pela chegada da chuva e pelo trabalho dela e de Fabiano na fazenda, enfim, pela melhora relativa de vida; a segunda é o medo de que a mudança de fortuna não se consolide e que todos tenham que voltar à estrada fugindo da seca. Nas duas projeções se evidenciam os limites (que não são naturais, é claro, mas sociais) impostos à ação humana e com eles um mundo recalcitrante, obstinado, que parece resistir a qualquer mudança. Tudo 
isso é apresentado ao leitor como uma situação concreta vivida pela personagem. A narrativa em terceira pessoa, mas em discurso indireto livre, é um recurso do autor para construir um narrador que se aproxima da personagem, preservando, porém, uma distância entre os dois. As reflexões sobre a condição de opressão e sobre as possibilidades de superá-la são da personagem e também do narrador, representante do escritor, um intelectual brasileiro dos anos 30 do século XX.

O leitor acompanha o movimento de sinha Vitória pela fazenda, um movimento dentro de um tempo enrijecido e convertido em espaço, em si mesmo uma espécie de confinamento. A fazenda é o espaço de produção da sobrevivência e reprodução da sujeição e domínio, não apenas de sinha Vitória e sua família, mas da sociedade representada no romance, o Nordeste brasileiro, o Brasil dos anos 30, mas com a dimensão universal própria da ficção de Graciliano Ramos.

Não é sequer o tempo de um dia, mas é o suficiente para que o leitor perceba a rotina de sinha Vitória. Ela executa tarefas, ao mesmo tempo, porém, pensa, reflete sobre sua condição, mistura recordações com o sonho, projeta expectativas, procura lidar com as ameaças, revolta-se às vezes, outras vezes se enternece. Mais do que isso, ela se bate contra os seus próprios limites e antevê a possibilidade de superá-los. Os limites se mostram em todos os momentos e lugares, parecem sobre-humanos, eternos. Parecem sujeitar os personagens, como se estes fossem meros joguetes.

As reflexões são muito mais amplas do que parecem, extrapolam a situação individual da personagem, como também a situação do grupo familiar. É uma reflexão sobre o país e sobre o mundo, conduzida pelo narrador, mas não como se este colocasse uma tese, sim como uma situação efetivamente vivida pelos personagens. O inesperado da situação está em que: $1^{\circ}$ ) a personagem, contrariando um preconceito de classe, pensa; $2^{\circ}$ ) o pensamento não se dá de modo disciplinado e metódico, mas de modo prático, por assim dizer, uma vez que o esforço por compreender a realidade se dá enquanto ela se movimenta em torno do fogo e da fazenda. Não se trata, portanto, em Vidas secas, da supremacia do pensamento lógico-racional, mas, sim, da afirmação da práxis como caminho para o conhecimento.

É uma situação dramática. A personagem pensa e discute com o leitor sobre o mundo. Na caminhada em torno da panela em que "prepara a boia", ela se pergunta "Em que estava pensando?" ou "Onde tinha a cabeça?" As perguntas são dirigidas também ao leitor, a quem também 
cabe organizar esse pequeno mas complexo mundo de experiências miúdas: "Em que estava pensando?" - na cama, na seca, no papagaio, na vida de bicho, na dignidade inalcançável...? -, "Onde tinha a cabeça?" em outro lugar para além daqueles limites na aparência intransponíveis? Como são duas projeções, o desejo e o medo se combinam e se repelem na imediatez vivida. O medo de que a seca retorne (a projeção ruim) e o desejo de possuir a cama (a projeção boa) perturbam a rotina.

As perguntas “Em que estava pensando?" e "Onde tinha a cabeça?" poderiam ser, num contexto bem diverso, formuladas por um personagem como Luís da Silva de Angústia. Mas a diferença é importante: Luís da Silva formula perguntas semelhantes, mas elas não geram respostas. Formuladas por sinha Vitória, elas impulsionam a personagem.

Sinha Vitória dialoga consigo mesma, mas tendo sempre presente o mundo objetivo da sua situação. E há uma lógica aí - a do mundo como ele está constituído, mas trazendo, dentro dele, a possibilidade de superá-lo. Cabe ao leitor elevar-se o suficiente para entender a sua complexidade: a possibilidade não é externa ao mundo como uma utopia, se constrói aí dentro desse mundo como sua superação. Sinha Vitória, embora confinada naquele tempo-espaço, não é um mero joguete da situação. Ela pensa. E se o desejo, a projeção boa, não pode ser realizado, a situação radicaliza-se. Com isso, a projeção má ganha outro sentido.

As sugestões do narrador são fortes: desde o início a "nuvem de cinza" parece já conter a possibilidade tão temida da seca. Outras nuvens depois se impõem, são nuvens também cinzas e de mau agouro, ameaças, entre elas a lembrança do papagaio, sacrificado num momento de absoluta miséria, o mormaço levantado da terra queimada, as folhas amarelas da catingueira. Sinha Vitória só tinha medo da seca, mas se tranquiliza quando vê que Fabiano ronca com segurança: "Provavelmente não havia perigo, a seca devia estar longe." (RAMOS, 2008, p. 44).

A rotina se impõe como uma situação extrema. Os limites que aprisionam sinha Vitória são de um mundo em que o tempo se converteu em espaço e que, como tal, parece não se abrir para o devir. Os sonhos não são só dela, pois representam a possibilidade extrema de superação do mundo recalcitrante. Situação e possibilidade extremas se apresentam como realidade a que não se pode escapar.

O capítulo é, como os demais, nem curto nem longo: tem a extensão que lhe é própria, é do tamanho que deve ser. Como capítulo de um romance - este, sim, uma unidade narrativa completa -, representa os 
confins do mundo em que vivem ou são obrigados a viver sinha Vitória e sua família. Aí tudo se presentifica: tempo e espaço, a dura realidade, o desejo, a ameaça, os habitantes da fazenda, o patrão, seu Tomás da bolandeira, o além da fazenda, a cidade longínqua, a estrada de onde vieram e para onde terão que voltar. O pequeno mundo de sinha Vitória inclui também o leitor no seu diálogo com o narrador, não apenas em decorrência do ato mesmo de leitura, mas também porque ele, leitor, é personagem dessa narrativa que é o Brasil e o sistema-mundo capitalista.

O leitor se depara com um mundo diminuído, estranha-o, mas logo percebe que ali não há qualquer complacência para com os personagens, nenhum paternalismo, e que o mundo diminuído não tem nada de pitoresco. As qualidades realistas são da escrita, mas também da sociedade que por meio dessa escrita radical tenta tomar consciência de si própria. Por não ser uma representação realista no sentido restrito e empírico do termo, que procurasse reproduzir nos seus detalhes o dia a dia da personagem, e como, pelo contrário, procura apresentar esse dia a dia na sua qualidade essencial, o narrador se restringe aos gestos decisivos. É um outro realismo, que reorganiza o mundo da experiência imediata, extraindo daí as conexões que teimam em se ocultar.

A qualidade realista de Vidas secas está, não em reproduzir a realidade extensiva, mas em evidenciar as suas conexões. Como as conexões não estão à vista, e é sobre elas que sinha Vitória tenta pensar, elas são mais do que reproduzidas, são produzidas pelo romance. Sobre elas tenta pensar o autor e cabe ao leitor também pensar. A mimèsis é ativa, é poièsis. A obra produz (no sentido aristotélico de ação produtiva, poética) o sentido. Em Vidas secas, porém, produzir o sentido não quer dizer inventar um sentido qualquer, quer dizer, sim, que o sentido da vida humana não está dado e depende da ação humana. Em "Sinha Vitória" a questão é, pois, esta: desumanizados, os personagens perderam de todo a condição de decidir sobre sua própria vida? A pergunta se volta também para o leitor. Sinha Vitória se inquieta: "Tinha de passar a vida inteira dormindo em varas?" (RAMOS, 2008, p. 44). O leitor, por sua vez, deve refazer a pergunta em outra perspectiva.

Essa questão é central quando se discute a especificidade do realismo brasileiro e, ainda mais, o realismo de Graciliano Ramos. A possibilidade de mudança histórica está presente no horizonte dos anos 30 do século XX no Brasil, como afirma João Luiz Lafetá (2000). Entretanto, mesmo dentro da obra de Graciliano Ramos convém diferenciar Vidas 
secas de Angústia. Não trataremos dessa questão aqui. Convém apenas ressaltar o traço épico de Vidas secas que, se não o faz melhor do que os demais romances do autor, confere-lhe uma particularidade: o conhecido pessimismo do autor cede lugar, não a um otimismo qualquer, mas a uma visão direcionada para o futuro.

Sobre pessimismo e otimismo em Vidas secas, convém ter em mente a observação de Carpeaux de que Vidas secas é o romance relativamente mais sereno, relativamente mais otimista de Graciliano. No seu magistral ensaio de 1978, Carpeaux visava a construir uma visão geral do romancista ("Vou construir o meu Graciliano Ramos", diz ele). Não há o que questionar no ensaio. O aspecto político, no sentido amplo, entretanto, deve ser ressaltado: enquanto João Valério, Paulo Honório e também Luís da Silva se encontram no instante final de um percurso histórico, sinha Vitória e Fabiano (e, ainda mais, os meninos), não estão presos a um projeto envelhecido, a não ser como as suas maiores vítimas. Não têm nada a perder.

Voltemos a "Sinha Vitória". Nesse capítulo, como nos demais, o narrador, graças ao discurso indireto livre, aproxima-se ou distancia-se do personagem, identificando-se ou distinguindo-se. Mas em nenhum momento aparece aquela condescendência, bastante comum na ficção brasileira do regionalismo pitoresco, que denuncia o sentimento de superioridade do intelectual. O narrador - mediação do escritor - não tem o domínio da situação, tampouco ele sabe aonde tudo aquilo vai dar. (O diálogo final do romance, de que participam sinha Vitória, Fabiano e também o narrador nos dá uma visão clara disso. Trataremos dele mais adiante.)

Aí temos o mundo visto por sinha Vitória. Não a visão de mundo de sinha Vitória, como algo cerrado, consolidado, ou uma ideologia, mas a representação do modo de como ela percebe e vivencia o mundo enquanto age e pensa. Da ascendência intelectual que ela tem sobre Fabiano, trataremos ao final.

Os limites estruturais dos personagens de Vidas Secas, aqueles que lhes impedem de transformar a vida e o mundo - a propósito deles a crítica também tem falado, às vezes, de modo abusivo, de rudeza, pobreza de linguagem e dificuldade de entender o mundo etc. - ganham na obra um sentido positivo: se transformam no lacônico estilo do escritor, estilo este tão ressaltado pela crítica e que dá a Graciliano Ramos um lugar único na ficção brasileira. Quer dizer: os limites não são aceitos passivamente pelo escritor, mas tomados como condição objetiva a ser 
superada. Os limites se convertem em força construtiva: não apenas a vida é seca, mas também a forma do romance. Vemos aí o trabalho do artista que visa, não apenas à constatação dos limites, mas à sua superação e à transformação da realidade.

Tomar os limites como intransponíveis, como condições que esmagam os personagens retirando deles qualquer possibilidade de superação significaria fazer da obra de arte uma simples constatação das condições desumanas. Daí o nosso capítulo potencializar o contraponto entre os sinais da seca que outra vez se avizinha e o desejo da cama de couro.

A cama de couro é o que vai além do mundo em que eles vivem, mas se projeta a partir dele. Afinal, ela traz em si a marca das relações humanas desiguais. Se ela não está disponível, entretanto invade a alma de sinha Vitória e termina por contaminar a rotina, dando-lhe um sentido diferente. O desejo não está disponível, mas é necessário continuar alimentando-o como ao fogo nas achas de angico. Aliás, o fogo é um símbolo central nessa narrativa: é o sol abrasador que virá com a seca e cujas labaredas queimarão a terra e os seres que nela vivem; é também uma força que mantém acesa a chama da vida.

O narrador valoriza o "primitivismo" dos personagens, porque eles guardam consigo algo que aqueles que o submetem perderam exatamente o caráter primitivo, o contato mais direto com a natureza, a dimensão telúrica (e talvez épica) da vida. Os que estão distante dali, o patrão, o próprio escritor e o leitor de Graciliano Ramos, habitam outra parte do mesmo mundo, ou um outro estágio seu-aquele em que o processo de fetichização já se completou. Poderão sinha Vitória e sua família reabrir esse processo, não tomá-lo por acabado, fazerem outra história?

O leitor na verdade acompanha o olhar do narrador que percorre esse mundo recalcitrante. O olhar percorre a fazenda, pousa nos objetos, nos animais, em Baleia, nos meninos e em Fabiano, que dorme. E esse movimento parece querer quebrar os limites, ir além da fazenda, pôr os pés na estrada.

Agir e pensar, a conjugação das duas coisas se repete com frequência em Vidas Secas. Veja-se a movimentação do menino mais novo, que procura imitar o pai e almeja ser como ele quando crescer; pense-se na movimentação do menino mais velho na sua luta por entender as palavras. A experiência de sinha Vitória no nosso capítulo é semelhante à de Fabiano em "O mundo coberto de penas". No capítulo "O mundo coberto de penas" a reflexão é tão forte que dá a impressão que Fabiano 
está de alguma forma lendo as vidas secas, não o romance evidentemente, mas a configuração que subjaz a ele. Ser um homem ou ser um bicho, pergunta Fabiano, e a pergunta reformula-se no questionamento de sinha Vitória: é impossível ter uma cama de couro e viver como gente?

As labaredas a incomodam, ela limpa o rosto. Baleia, por sua vez, se encanta com as estrelinhas vermelhas e pelo seu encantamento ganha um pontapé, injusto. Os meninos são deixados longe e Fabiano, dorme. O mundo é só dela e do seu desejo. Mas não é um desejo solitário, ela pensa pelo grupo. É um desejo coletivo.

A contraposição das duas experiências é organizada pelo narrador. Desde o início do capítulo - quando o que a move no íntimo é o desentendimento com Fabiano sobre a cama - as faíscas e as labaredas do fogo da comida que ela prepara lhe trazem o pressentimento do retorno da seca. Ela caminha de um para outro lado, zanga-se com Baleia, controla os meninos e a vaca laranja. Ela amanhecera "nos seus azeites". O desentendimento foi forte e grande. Eles trocaram agressões. Fabiano criticara os gastos com o sapato de verniz que, além de caro, não cabiam direito nela. Ele chegara a compará-la com o papagaio de triste memória. Ela revidara lembrando que Fabiano gastava dinheiro na feira com bebida e jogos.

Mas agora ela está só e procura refletir sobre tudo isso. Fabiano ainda dorme e ronca. Ela caminha, o leitor segue-a pelos quatro cantos da fazenda. Ela caminha, e pensa. É admirável a composição dos parágrafos em que as ações de sinha Vitória vão sucedendo-se uma às outras, aparentemente a esmo, mas num ritmo de quem percorre o pequeno mundo onde habita e demarca outra vez os seus limites. O mundo é um espaço de confinamento e superá-lo significa retomar o tempo como devir.

Sinha Vitória em nenhum momento se anula. Permanece sempre querendo entender o que se passa com ela. Jamais abdica disso: os acontecimentos têm sentido, embora sejam meio misteriosos. Convém, então, entender que o que se passa com ela, ou seja, o conjunto de ações que configuram o romance evoca o que se passa no país. "Onde tinha a cabeça” é uma pergunta que dá bem a ideia das limitações de entendimento da situação brasileira.

Em Vidas Secas os esquemas que estavam à disposição do homem comum do povo, mas também dos intelectuais naquele momento, se revelam inoperantes. Aí Graciliano narra as dificuldades de entendimento do país. As mudanças ocorridas nos anos 30 não resolveram os problemas anteriores. A falsa modernização não foi capaz de dar uma nova forma 
ao país. A situação colonial e o escravismo não foram abolidos, apenas ganharam nova roupagem. Mas quais são as novas perspectivas? Em que estavam todos pensando? Fabiano e sinha Vitória tentam à sua maneira pensar sobre isso. O intelectual Graciliano Ramos também. Aí ele se coloca na contramão do ideário paternalista da esquerda de sua época, que pregava a necessidade de doutrinar o homem do povo.

Mas os pensamentos de sinha Vitória são complexos. Ela é capaz de formular perguntas históricas. Se não tem as respostas, tampouco as tem o intelectual. As elites brasileiras dos anos 30 do século XX não sabem bem onde têm a cabeça nem em que estavam pensando. Apenas acomodam-se ao novo estágio do capitalismo e se organizam para tirar algum proveito da sua renovada condição colonial. Uma situação estável, ao que parece. Mas os pensamentos de sinha Vitória vão noutra direção: é preciso desfazer a estabilidade, construir um outro caminho com os seus pés de andarilha.

O leitor acompanha o movimento de sinha Vitória pelo espaço de confinamento e é levado, pelo trabalho do escritor, a pensar nas perguntas históricas que ela formula dentro do seu "horizonte acanhado".

As perguntas são também do narrador, como já dissemos, mas são colocadas com a objetividade da terceira pessoa. Na verdade, Vidas secas não poderia ser mais um romance em primeira pessoa, como são os três primeiros do autor. Se em $S$. Bernardo, romance em primeira pessoa, o protagonista Paulo Honório é um antigo trabalhador da roça que ascendeu na escala social e quer, então, narrar a sua história, sinha Vitória e os seus ainda não completaram os seus périplos, a sua história não está aí para ser narrada como algo já feito e terminado. Paulo Honório contempla os seus destroços. Quanto aos personagens de Vidas secas não há destroços para narrar e contemplar. Há chão para andar. (Decorreria disso o relativo otimismo que Carpeaux assinala em Vidas secas?)

A princípio, Fabiano pensa que, economizando na roupa e no querosene, poderiam comprar a cama de lastro de couro. Isso logo se mostra impossível: sinha Vitória lembra que eles já se vestiam mal, as crianças andavam nuas, e já se privavam de luz ao anoitecer. Eles se desentendem, e foi por isso que ela acordou "nos seus azeites".

É então que, enfrentando a impossibilidade de adquirir a cama, sinha Vitória se pergunta "em que estava pensando". Percebe que tinha se distraído, procura se concentrar e olha o chão, vê os pés de andarilha, o que sugere a seca e a fuga. 
Sinha Vitória esquecera o passado, a vida começara na fazenda, onde desfrutam de uma vida melhor, até mesmo de "um começo de prosperidade". Eles "eram quase felizes". O que aperreia sinha Vitória era não ter direito à cama. $\mathrm{O}$ pensamento dela vagueia e o leitor o segue. É preciso muito esforço para isolar o objeto do desejo, diz o narrador, e esse esforço não cabe apenas a sinha Vitória, mas também ao leitor.

A cama afinal se mostra como inatingível e de alguma forma misteriosa. Suscita associações extravagantes. Chupando o cachimbo, a personagem lança uma cusparada que atravessa a janela e vai cair no terreiro. Como num pensamento mágico, imagina que, se cuspisse outra vez e a cusparada atingisse o terreiro, "a cama seria comprada antes do fim do ano." Mas falha várias vezes. O pensamento mágico se revela ineficaz. Sinha Vitória é posta à prova na sua experiência cultural. As rezas e curas tão corriqueiras em Vidas secas são questionadas. Mas não numa posição de arrogância do narrador intelectual que pregasse a superioridade do pensamento lógico-racional. Trata-se, antes, de uma questão histórica, no sentido de que esses momentos são para os personagens momentos extremos que exigem um novo exercício da percepção e do entendimento. Sinha Vitória e sua família são postas à prova a cada momento, o que culmina no capítulo final. O narrador une-se a eles, numa reflexão sobre o momento histórico do Brasil. As situações exigem superação.

Não convém tomar a cama de vara como uma alegoria. Não há aí a transcendência alegórica. Não é tampouco um simples sinal de status. É a condição humana física da vida. Um lugar onde o casal pode dormir como gente. Não é um geral que se particulariza num exemplo. Lukács na sua Estética cita Goethe a propósito da diferença entre símbolo e alegoria: se o poeta busca a singularidade correspondente ao geral, nasce a alegoria; se vê o geral no singular, nasce o símbolo. Na alegoria o singular é um exemplo. Pelo contrário, aquele que capta vivamente a singularidade recebe ao mesmo tempo com ela o geral, sem dar-se conta ou dando-se conta disso mais tarde. O singular representa o geral, não como sombra ou sonho, mas como revelação viva e instantânea dele (GOETHE apud LUKÁCS, 1967, p. 424).

O pequeno mundo de sinha Vitória se mostra todo ao leitor, mas este se enganará se tomar essas coisas miúdas como exóticas e pitorescas. Há nelas a gravidade da tragédia, a reversão da fortuna que se avizinha. Então, se não é possível realizar o desejo de ter uma cama igual à de seu Tomás da bolandeira, a outra situação extrema se impõe. O desejo de dignidade humana é inalcançável naquelas condições. 
No capítulo final, "Fuga", todas as questões se recolocam outra vez, mas como numa síntese poderosa. As situações e reflexões anteriores são potencializadas. (Vê-se, assim, que Vidas secas é uma unidade narrativa e que a expressão "romance desmontável", usada por Rubem Braga para caracterizar o romance, deve ser entendida com cautela; cf. BUENO, 2006.)

Acompanharemos agora o diálogo de sinha Vitória com Fabiano do capítulo final. Na caminhada, são "quatro sombras no caminho estreito coberto de seixos miúdos." Os meninos vão à frente, andam mais rápido. Baleia já não existe, converteu-se num remorso. O seu sacrifício, nunca plenamente justificado, agora pesa como nunca. Sinha Vitória e Fabiano podem rever toda a experiência passada e tentar entender o momento extremo.

Ela "tinha sempre razão" - pensa Fabiano sobre sinha Vitória. Mas, e se em outras paragens ele não puder vaquejar, poderá fazer outras coisas, poderá ter outras ocupações. Sinha Vitória combatia as dúvidas de Fabiano:

Por que não haveriam de ser gente, possuir uma cama igual à de seu Tomás da bolandeira? [...] Por que haveriam de ser sempre desgraçados, fugindo no mato como bichos? Com certeza existiam no mundo coisas extraordinárias. Podiam viver escondidos, como bichos? Fabiano respondeu que não podiam.

— O mundo é grande. (RAMOS, 2008, p. 123).

As palavras de sinha Vitória encantam Fabiano, convencem-no. "Sim senhor. Que mulher!" - ele pensa. Aqui a magia retorna, e sinha Vitória não deixa de ter uma dimensão, não sobre-humana, mas de valor humano mais elevado. Tomado por essa força, Fabiano passa a acreditar que eles "Iriam para diante, alcançariam uma terra desconhecida." E então se dirigem convencidos para o sul.

As duas expectativas em torno das quais se organiza o capítulo "Sinha Vitória", que se revelam inicialmente como opostas, de certa forma se conjugam ao final: abandonar a fazenda, voltar à estrada, e agora em direção ao sul, se apresenta como a única forma possível de 
alcançar a dignidade humana que a cama de seu Tomás da bolandeira inicialmente simboliza. A fazenda, que no início do romance é o oásis no deserto, agora é o espaço do confinamento. O deserto se expandiu, recobriu o oásis. O mundo recalcitrante é o mesmo do início, se reproduz, mas, ao se reproduzir, se reestrutura. A cama desejada e a seca temida se opõem, mas uma termina se revelando na outra. No fim, quando a seca obriga-os a abandonar a fazenda e voltar à estrada, é o desejo de conquistar dignidade humana que lhes dá esperança. Era aí é que sinha Vitória tinha a cabeça.

A fuga para a estrada é uma possibilidade extrema tornada real pela ausência de condições de permanecer na fazenda: "A vida na fazenda tornara-se difícil." A relativa melhora é passageira. A rotina então é quebrada e em seu lugar nada se coloca. O capítulo final é uma discussão sobre os destinos da família e também sobre os rumos da história. Trata-se de uma fuga antes de tudo, porque eles não se despedem do patrão: "Não poderia nunca liquidar aquela dívida exagerada. Só lhe restava jogar-se ao mundo, como negro fugido." (RAMOS, 2008, p. 117). Mas, ao final, Fabiano e sinha Vitória passam a entendê-la como mudança.

Após caminharem três léguas, param para um breve descanso. A incerteza toma conta ainda de Fabiano. Ele ainda não acredita que aquilo seja de fato mudança. Depois de algum tempo, sinha Vitória aproxima-se dele. Ela precisa falar. Aproxima-se dele, buscando amparo, e dá início a uma longa conversa. Falam do passado confundido com o futuro. Ela pergunta "Não poderiam voltar a ser o que já tinham sido?" A pergunta parece despropositada a Fabiano ("palavras incompreensíveis") e, seguramente, para nós leitores também. Fabiano anda meia légua antes de tentar responder. O leitor terá alguma dificuldade em entender a relação entre as perguntas e as respostas. Mas aí vai se decidir qual a direção que de fato tomarão.

Fabiano demora em responder e quando o faz formula também algo difícil: "A princípio quis responder que evidentemente eles eram o que tinham sido; depois achou que estavam mudados, mais velhos e mais fracos. Eram outros para bem dizer." (RAMOS, 2008, p. 121). Mais do que difícil, a resposta, para manter-se no nível da pergunta, assume um tom meditativo, revelando a presença forte do narrador.

A resposta de Fabiano parece traduzir a pergunta de sinha Vitória dando-lhe um sentido mais palpável. Mas ela insiste: "Não seria bom tornar a viver como tinham vivido, muito longe?" Fabiano hesita em 
responder. "Talvez fosse, talvez não fosse" - se o longe é uma casinha protegida pela bolandeira de seu Tomás, então tudo bem, mas na fazenda viveriam sempre assustados.

Com as respostas aproximamo-nos do mundo da experiência concreta dos personagens. As perguntas, entretanto, podem ser entendidas de outra forma: eles eram o que tinham sido - seres humanos reais, mas sua humanidade foi expropriada, sua vida foi consumida no trabalho que dá lucro ao patrão. Por isso são outros hoje, diversos do que são. Fabiano se volta querendo ainda ver a fazenda que deixara para trás. Depois repele a lembrança: "Que fazia ali virado para trás?"

É difícil concordar com alguns críticos de Vidas secas que veem o romance como um ciclo reproduzindo algo como o eterno retorno. $\mathrm{O}$ capítulo "Fuga" problematiza a repetição, questiona passado, presente e futuro. É necessário tomar um rumo diverso do que vinha sendo tomado, que era procurar abrigo na fazenda quando chegam as chuvas. Sinha Vitória e Fabiano recusam repetir a experiência. E nesse sentido que convém entender os capítulos "Sinha Vitória" e "O mundo coberto de penas" como momentos de autoconsciência dos personagens. (À sua maneira, os capítulos "O menino mais novo" e "O menino mais velho" são também momentos de provação no caminho do amadurecimento dos dois meninos.)

No parágrafo final do capítulo várias vozes se cruzam: a de sinha Vitória, que prefere enfrentar o desconhecido a continuar aquela vida de bichos (assim ela expressa sua esperança na viagem); a de Fabiano, que desconfia, mas se encanta com as palavras dela - ele fica contente e termina por acreditar nessa terra "porque não sabia como ela era nem onde era"; a do narrador que, embora não desqualifique as palavras deles, se mantém a uma distância crítica.

O diálogo final entre sinha Vitória e Fabiano é possível porque os dois, apesar de tão próximos e aparentemente idênticos, guardam valiosas diferenças entre eles. O leitor de Vidas secas não terá muita dificuldade em perceber que ela tem uma superioridade intelectual em relação a ele. Entretanto, é mais difícil entender o que a superioridade significa e como ela funciona no romance. Ela é funcional porque permite o diálogo: Fabiano tem o que aprender com sinha Vitória, e essa aprendizagem tem valor, não só para ele, como para o grupo. Além do mais, essa aprendizagem entra no lugar daquela que valorizava o papel do intelectual e sua supremacia sobre o homem do povo. Ela significa que o povo tem a aprender consigo mesmo. 
Nesse sentido, se entende também a distância crítica do narrador. Muitas vezes ele enfatiza a superioridade, mas não a toma como fato consumado. O diálogo é um processo, e isso não significa simplesmente desvalorizar Fabiano frente a sinha Vitória. Significa que a realidade é de difícil entendimento, mas que pode ser entendida. Deve-se dizer ainda que se a realidade pode ser entendida, não é de uma vez para sempre, mas como situações que se renovam. Por isso os personagens também se renovam. E daí também a importância do diálogo entre os dois personagens.

\section{Referências bibliográficas}

BUENO, Luís. Uma história do romance de 30. São Paulo: Edusp, 2006. CARPEAUX, Otto Maria. Visão de Graciliano Ramos. In: BRAYNER, Sônia (Org.). Graciliano Ramos. Rio de Janeiro: Civilização Brasileira, 1978.

LAFETÁ, João Luiz. 1930: a crítica e o modernismo. São Paulo: Duas Cidades; Editora 34, 2000.

LUKÁCS, Georg. Estética. Barcelona: Grijalbo, 1967. v. 4

RAMOS, Graciliano. Vidas secas. 105. ed. Rio de Janeiro: Record, 2008. 